\title{
HUBUNGAN ANTARA MOTIVASI BELAJAR DAN MINAT BACA SISWA DENGAN HASIL BELAJAR FISIKA SISWA KELAS VIII SMP PGRI 2 SEKAMPUNG
}

\author{
Ayang Kinasih', Erni Mariana ${ }^{2}$ \\ 1,2Pendidikan Fisika, Universitas Nahdlatul Ulama Lampung, Lampung Timur \\ e-mail: kinasihayang@gmail.com, marianaerni558@gmail.com
}

\begin{abstract}
Proses pendidikan di sekolah disamping guru mempersiapkan proses pembelajaran perlu ditunjang pula kreativitas siswa, misalnya dalam bentuk memberikan motivasi belajar dan minat baca dari dalam diri siswa. Tujuan dari penelitian ini adalah untuk mengetahui Hubungan antara Motivasi Belajar dan Minat Baca Siswa dengan Hasil Belajar Fisika Siswa SMP PGRI 2 Sekampung semester genap tahun pelajaran 2020/2021. Jenis penelitian ini adalah Korelasi dengan subjek penelitian adalah siswa kelas VIIlc SMP PGRI 2 Sekampung yang terdiri dari 36 siswa sebagai sampel.Rancangan penelitian yang telah dilakukan dalam penelitian ini adalah penelitian yang bersifat kuantitatif. Hasil penelitian tersebut, maka dapat ditarik kesimpulan bahwa Ada hubungan yang signifikan antara motivasi belajar siswa dan minat baca siswa dengan hasil belajar fisika siswa. Hal ini terlihat pada $f_{\text {hit }}>$ $f_{\text {daf }}$ bernilai positif artinya motivasi belajar dan minat baca siswa sebesar $33,3 \%$ dalam meningkatkan hasil belajar fisika siswa.
\end{abstract}

Kata Kunci: Motivasi Belajar, Minat Baca, Hasil Belajar Fisika

Educational processin theschool, in addition tolearningthe process ofpreparingteachersto be supportedalsothe creativityof students, for examplein the form ofprovidingmotivationandinterest in readingof the student. The purpose of this study was to determine the relationship between student learning motivation and reading interest and the physics learning outcomes of students at SMP PGRI 2 Sekampung even semester of the 2020/2021 school year. This type of research is a correlation with the research subject being students of class VIIIC SMP PGRI 2 Sekampung which consists of 36 students as a sample. The research design that has been carried out in this research is quantitative research. The results of this study, it can be concluded that there is a significant relationship between student learning motivation and student reading interest with student learning outcomes of physics. This can be seen in the $f_{\text {hit }}>f_{\text {daf }}$ positive value ofwhich means that students' learning motivation and reading interest is $33.3 \%$ in improving student learning outcomes of physics.

Keywords: Learning Motivation, Reading Interest, Physics Learning Outcomes

\section{Pendahuluan}

Pendidikan merupakan proses untuk membantu dalam pengembangan dirinya sehingga mampu menghadapi segala perubahan dan permasalahan dengan sikap terbuka serta pendekatan kreatif tanpa kehilangan identitas diri. Belajar menghasilkan perubahan prilaku pada peserta didik. Perubahan tersebut terjadi sebagai hasil latihan, pengalaman dan pengembangan yang hasilnya tidak dapat diamati secara langsung. Belajar adalah aktivitas mental/psikis yang berlangsung dalam interaksi aktif dengan lingkungan yang menghasilkan perubahan-perubahan dalam pengetahuan, keterampilan, dan sikap.Untuk menjadikan anak didik sebagai pelajar yang berprestasi baik, memang tidak mudah, banyak syarat yang harus dipenuhi. Seperti halnya guru harus mempersiapkan anak didik agar mampu menghadapi masa depan yang lebih baik dengan cara mendewasakan anak didik dalam kecerdasan, kepribadian luhur, memiliki keterampilan dan pengetahuan luas.Dalam proses pendidikan di sekolah, disamping guru mempersiapkan proses pembelajaran perlu 
ditunjang pula kreativitas siswa, misalnya dalam bentuk memberikan motivasi belajar dan minat baca dari dalam diri siswa.

Hasil studi PISA 2018 yang dirilis oleh OECD menunjukkan bahwa kemampuan siswa Indonesia dalam membaca, meraih skor rata-rata yakni 371, dengan rata-rata skor OECD yakni 487. Kemudian untuk skor rata-rata sains mencapai 389 dengan skor rata-rata OECD yakni 489. Hal ini menunjukkan bahwa kemampuan membaca dan sains siswa di indonesia berada di bawah rata-rata skor siswa dari negara yang masuk dalam anggota OECD. Hal ini juga diperkuat dengan hasil penelitian (Mulyani \& Nurliana, 2017) yang menyatakan bahwa Semakin tinggi minat baca yang dimiliki oleh siswa akan memberikan pengaruh yang signifikan terhadap peningkatan kemampuan membacanya. Berdasarkan hasil prasurvei di SMP PGRI 2 Sekampung khususnya untuk hasil belajar fisika siswa yang masih rendah diduga karena dipengaruhi oleh beberapa faktor diantaranya kurangnya motivasi belajar dan minat baca dari siswa. Untuk memberikan gambaran terhadap masalah yang ada di lokasi penelitian, maka akan dikemukakan hasil pra survei yang berupa data hasil belajar fisika siswa SMP PGRI 2 Sekampung.

Tabel 1. Data Hasil Nilai Mid Semester Fisika Siswa Kelas VIII Semester Ganjil Tahun Pelajaran 2020/2021.

\begin{tabular}{c|c|c|c|c}
\hline No & Nilai & Kriteria & Jumlah Siswa & Presentase $\%$ \\
\hline 1 & $\geq 70$ & Tercapai & 56 & 25 \\
\hline 2 & $<70$ & Belum Tercapai & 170 & 75 \\
\hline \multicolumn{2}{|c|}{ Jumlah } & 226 & 100 \\
\hline
\end{tabular}

Dari tabel 1 di atas dapat dilihat bahwa hasil belajar fisika siswa kelas VIII semester ganjilSMP PGRI 2 Sekampung masih ada siswa yang belum tuntas, Dengan KKM (Kriteria Kelulusan Minimum) yang ditetapkan untuk mata pelajaran fisika adalah 70, jadi siswa yang memperoleh nilai kurang dari 70 dikatakan hasil belajarnya belum tuntas. Kegiatan belajar merupakan kegiatan yang paling pokok dari keseluruhan proses pendidikan disekolah dan dirumah. Hal ini berarti bahwa berhasil atau tidaknya pencapaiannya tujuan pembelajaran antara lain tergantung kepada bagaimana kegiatan belajar yang dijalani siswa tersebut sebagai peserta didik. Salah satu ukuran keberhasilan pembelajaran dapat dilihat dari hasil belajar.Banyak faktor yang mempengaruhi rendahnya hasil belajar diantaranya: siswa tidak memperhatikan penjelasan guru, siswa malas mengerjakan tugas yang diberikan guru, siswa pasif dalam proses pembelajaran dan siswa malas mencatat materi telah disampaikan oleh guru, berdasarkan hasil pengamatan kelas yang telah dilakukan pada saat proses pembelajaran berlangsung banyak siswa yang mengobrol sendiri, tidak memperhatikan penjelasan guru pada saat pelajaran, bahkan ada beberapa siswa yang sibuk bermain $\mathrm{Hp}$. Sejalan dengan Pendapat (Mariana, 2018) menyatakan bahwa hasil belajar siswa yang dalam proses pembelajarannya menggunakan perangkat pembelajaran yang lengkap dan digunakan secara efektif dengan siswa yang dalam proses pembelajarannya menggunakan perangkat pembelajaran. Pada saat disuruh mengerjakan tugas yang diberikan oleh guru mereka malas, tidak ada minat untuk mengerjakannya, mereka hanya mengandalkan mencontek pekerjaan teman yang pintar. Hal ini lah yang diduga mempengaruhi hasil belajar yang rendah. (Ebrahim, 2016) menyatakan bahwa However, on average, non-governmental school students' achievements were better than governmental school students. In factor analysis, self-concept, motivation to the subjects and teaching-learning process explained most of the variations. Multivariate regression results revealed that, the factors, sex, school type, school facilities, family status, school volume, interest to the subject, motivation to the subject, self-concept, safe reading and trouble (anxiety) to the subjects, had significant influence on achievements of students with respect to most of the subjects. Factors like sex, school facility, family status, motivation to the subject, interest to the subject had a significance positive impact on achievements. However, trouble of the subject and school volume had a significant negative influence on students' achievements on Biology, Physics and English subjects. It is suggested that academic facilities and managements at schools, beside home and students' personal efforts need to be promoted for better academic 
achievements of students in subjects. (SARI, 2018) Terdapat faktor internal yang mampu mempengaruhi tinggi atau rendahnya hasil dari belajar siswa. Faktor tersebut diantaranya adalah minat untuk membaca dan motivasi untuk belajar. Jadi semakin tingginya minat baca serta motivasi belajar yang dimiliki siswa, akan memiliki dampak pada meningkatnya hasil belajar siswa. Dengan demikian, ketika siswa mempunyai kemauan yang tinggi untuk melakukan kegiatan membaca serta mempunyai motivasi tinggi terhadap belajar, akan meningkatkan hasil belajarnya siswa.

(Fitrianingsih et al., 2017) menyatakan bahwa salah satu penyebab rendahnya minat baca adalah motivasi belajar. Dalam hal ini upaya yang dapat dilakukan oleh guru bimbingan dan konseling dengan pemberian layanan bimbingan dan konseling dan melakukan kolaborasi dengan guru mata pelajaran dan orang tua siswa dalam meningkatkan motivasi belajar siswa. Salah satu layanan yang dapat diberikan oleh guru bimbingan dan konseling dalam meningkatkan motivasi belajar siswa yaitu dengan pemberian layanan bimbingan kelompok teknik homeroom. (safitri, A. Hasmunir. Kamaruddin, 2017) Minat membaca sebagai orientasi pengajaran menuntut cara belajar yang terarah, semakin sering berlatih akan mampu fasih serta terampil berbahasa. Begitu juga dengan minat membaca, apabila siswa berlatih secara terus menerus, maka mereka akan terampil dan meningkat keterampilan membacanya. Minat membaca, tidak hanya sekedar membaca teks, tetapi juga memahami apaisiteks. Apabila siswa sudah memahami dan mengungkapkan kembali isi bacaan baik secara lisan maupun secara tulisan, berarti siswa tersebut sudah dalam kategori terampil membaca. (Kusuma, 2017) menyatakan bahwa The purpose of the particular article is to increase the motivation and interest in reading that is needed to counteract the hoax in media. An explanatory method is used as the method. The author summarizes into three parts. The first is hoaxes and literacy, second, motivation and reading interest, and the third is an effort to increase the reading interest. Menurut (Nursalina \& Budiningsih, 2014) menyatakan bahwa minat baca merupakan hasrat yang kuat seseorang baik disadari ataupun tidak disadari lewat perilaku membacanya.

(Charli et al., 2019) menyatakan bahwa pengaruh langsung yang terjadi pada full day school dan gerakan literasi sekolah terhadap hasil belajar menunjukkan bahwa hasilnya tidak signifikan sehingga dapat disimpulkan bahwa hasil belajar dapat dipengaruhi oleh faktor internal maupun eksternal. Sementara itu, pengaruh full day school dan gerakan literasi sekolah secara signifikan berpengaruh terhadap motivasi belajar dan motivasi belajar berpengaruh terhadap hasil belajar. Dengan demikian, dapat disimpulkan jika siswa memiliki motivasi belajar yang besar dalam dirinya, ia akan mampu mencapai hasil belajar yang maksimal dan begitu juga sebaliknya. Oleh karena itu, minat dan motivasi belajar siswa harus selalu ditumbuhkan karena kegagalan dalam belajar tidak hanya disebabkan oleh pihak siswa, tetapi mungkin dari guru yang tidak berhasil menumbuhkan motivasi belajar siswa sehingga minat belajar siswa menurun dan semangat belajar menjadi semakin berkurang. Sehingga seorang guru dituntut agar mampu berperan sebagai motivator yang sangat berperan penting dalam meningkatkan kegairahan dan pengembangan kegiatan belajar siswa. (Ulfah et al., 2015) menjelaskan bahwa siswa yang memiliki minat dan motivasi yang kuat dengan siswa yang memiliki minat dan motivasi yang lemah akan terdapat perbedaan. Perbedaan tersebut akan nampak jelas dengan adanya ketekunan dan upaya untuk berhasil dalam belajar.Begitu pula dalam proses belajar mengajar dalam mata pelajaran Fisika. Tinggi rendahnya minat dan motivasi belajar siswa dalam mata pelajaran Fisika tentunya akan memberikan pengaruh terhadap hasil belajar yang akan diperoleh siswa.Supaya proses pembelajaran bisa berjalan dengan efisien, guru wajib tingkatkan peluang belajar untuk siswa baik mutu ataupun kuantitas. Peluang belajar siswa bisa ditingkatkan dengan metode mengaitkan siswa secara aktif dalam belajar. Guru wajib menampilkan intensitas dikala mengajar sehingga bisa membangkitkan minat dan motivasi siswa untuk belajar. (Khairuddin, 2013) menyatakan bahwa From this study, it is found that students have relatively low interests in reading English materials and that there is a significant difference between male and female students. From these findings, it can be suggested that stakeholders should take action with regards to developing and enhancing male students' reading interests. It is hoped that the finding of this study would enlighten the 
relevant literature of the area. Berdasarkan latar belakang masalah dan penelitian terdahulu maka peneliti merumuskan Tujuan dari penelitian ini adalah untuk mengetahui Hubungan antara Motivasi Belajar dan Minat Baca Siswa dengan Hasil Belajar Fisika Siswa SMP PGRI 2 Sekampung semester genap tahun pelajaran 2020/2021.

\section{Metode}

Rancangan penelitian ini merupakan penelitian Ex Post Facto karena variabel bebas dalam penelitian ini tidak dikendalikan atau diperlakukan khusus melainkan hanya mengungkap fakta berdasarkan pengukuran gejala yang telah ada pada diri responden sebelum penelitian ini dilaksanakan. Pada penelitian ini jenis penelitian yang akan dilakukan adalah korelasi atau hubungan, yang bertujuan untuk mengetahui adanya hubungan antara Motivasi belajar dan minat baca dengan hasil belajar fisika siswa SMP PGRI 2 Sekampung semester genap tahun pelajaran 2020/2021 yang berjumlah 36 siswa diambil dari seluruh populasi.

Instrumen pengambilan data yang digunakan adalah kuesioner untuk memperoleh data motivasi belajar dan minat serta tes hasil belajar fisika untuk memperoleh data hasil belajar fisika siswa.Kemudian analisis yang digunakan untuk menguji hipotesis adalah teknik analisis korelasi sederhana dan uji F. Namun sebelum dilakukan analisis tersebut, terlebih dahulu dilakukan uji persyaratan analisis yaitu uji normalitas sebaran data, uji lineritas data dan uji multikolinearitas data. data dianalisis dengan menggunakan SPSS 16.0 Software for windows.

\section{Hasil dan Pembahasan}

Tabel 1. Ringkasan hasil uji hipotesis penelitian

\begin{tabular}{|l|l|l|l|l|l|l|}
\hline $\begin{array}{l}\text { Persamaan garis } \\
\text { regresi }\end{array}$ & $\mathbf{r}_{\mathbf{x y}}$ & $\mathbf{r}_{\text {tab }}$ & $\mathbf{r}_{\mathbf{y}}$ & $\mathbf{R}_{\mathbf{y}}{ }^{2}$ & $\begin{array}{l}\mathbf{S E} \\
(\%)\end{array}$ & Ket. \\
\hline $\mathrm{Y}=17.335+0.040 \mathrm{X}_{1}$ & 0,4168 & 0,304 & - & - & 0,01 & Signifikan \\
\hline $\mathrm{Y}=6.202+0.172 \mathrm{X}_{2}$ & 0,5159 & 0,304 & - & - & 0,09 & Signifikan \\
\hline $\begin{array}{l}\mathrm{Y}=4.001+0,030 \mathrm{X}_{1}+ \\
0,170 \mathrm{X}_{2}\end{array}$ & - & - & 0,322 & 0,103 & - & Signifikan \\
\hline
\end{tabular}

Keterangan:

$\mathrm{X}_{1}=$ Skor minat belajar

$\mathrm{X}_{2}=$ Skor motivasi belajar

$\mathrm{Y}=$ Skor hasil belajar

Dari tabel 1 di atas maka dapat diketahui persamaan Regresi $Y$ atas $X 1$ adalah $\hat{Y}=$ $17.335+0,040 \times 1$. Berdasarkan analisis dengan menggunakan SPSS besarnya rhitung $=$ 0,4168 dengan $\mathrm{R} 2=0,173=17,3 \%$ dan di konsultasikan dengan $\mathrm{r}$ tabel product moment $\mathrm{n}=$ $42=0,304$, signifikan pada $\alpha=0,05$. Hal ini berarti hipotesis penelitian (Ha) yang diajukan, yaitu "terdapat hubungan yang signifikan antara minat belajar dengan hasil belajar. Berdasarkan hasil analisis tersebut dapat disimpulkan bahwa terdapat hubungan yang signifikan antara minat belajar dengan hasil belajarfisika melalui persamaan regresi $\hat{Y}=$ $17.335+0,040 \times 1$ dengan kontribusi sebesar $0,8 \%$ dan sumbangan efektifnya sebesar $0,01 \%$. Hal ini berarti makin tinggi minat belajar siswa maka makin tinggi pula hasil belajarfisika siswa. Sumbangan efektif (SE) variabel minat belajar dengan hasil belajar sebesar $0,01 \%$. Dengan demikian, minat belajar tidak terlepas sebagai faktor yang berkontribusi dengan hasil belajar fisika. 


\section{Hubungan antara minat baca dengan hasil belajar fisika}

Berdasarkan pengujian hipotesis antara motivasi belajar siswa dengan hasil belajar fisika ditunjukkan dengan koefisien korelasi sebesar 0,4168 dan koefisien determinasi parsial sebesar 0,173, artinya kontribusi motivasi belajar terhadap hasil belajar adalah 17,3\% dalam meningkatkan hasil belajar fisika siswa. Tolak $\mathrm{H}_{0} j \mathrm{jka} \mathrm{t}_{\mathrm{it}} \geq \mathrm{t}_{(1-1 / 2 \mathrm{a})(\mathrm{k}, \mathrm{n}-\mathrm{k}-1)}$ pada taraf signifikansi $\alpha=5 \%$, dari perhitungan di atas diperoleh $t_{\text {hit }}=2,90$ dan $t_{\text {daf }}=1,68$, dengan demikian $t_{\text {hit }}>t_{\text {daf }}$. Dengan kata lain $\mathrm{H}_{0}$ ditolak dan $\mathrm{H}_{1}$ diterima, yang berarti koefisien korelasi parsial cukup berarti. Siswa yang memiliki motivasibelajar baik hasil belajarnya akan baik. Hal ini menunjukkanbahwa hipotesis ada hubungan yang cukup erat antara motivasi belajar dengan hasil belajar fisika siswa terbukti.

Dari penelitian yang dilaksanakan oleh (Nurdin, 2012) menjelaskan minat baca yang terdapat pada siswa mempunyai pengaruh signifikan pada prestasi belajar siswa. Hal tersebut menyimpulkan bahwa salah satu dari faktor penentu keberhasilan belajar adalah minat untuk membaca yang dimiliki oleh siswa.

Berdasarkan hasil membagikan angket dan lembar observasi motivasi belajar dan analisis di atas tenyata motivasi belajar siswa pada pelajaran fisika mempengaruhi hasil belajar. Terlihat dari siswa yang aktif, memiliki kemauan, dan keinginan dalam mengikuti proses pembelajaran fisika maka akan mendapatkan hasil belajar yang baik.

\section{Hubungan antara minat baca dengan hasil belajar fisika}

Berdasarkan pengujian hipotesis antara minat baca siswa dengan hasil belajar fisika ditunjukkan dengan koefisien korelasi sebesar 0,5159 dan koefisien determinan sebesar 0,266 , artinya kontribusi minat baca terhadap hasil belajar adalah $26,6 \%$ dalam meningkatkan hasil belajar fisika siswa. Tolak $\mathrm{H}_{0} j \mathrm{ika} t_{\text {hit }} \geq \mathrm{t}_{(1-1 / 2 \alpha)(k, n-k-1)}$, pada taraf signifikansi $\alpha=5 \%$, dari perhitungan di atas diperoleh $t_{\text {hit }}=4,03$ dan $t_{\text {daf }}=1,68$, dengan demikian $t_{\text {hit }}>t_{\text {daf }}$. Dengan kata lain $\mathrm{H}_{0}$ ditolak dan $\mathrm{H}_{1}$ diterima, yang berarti koefisien korelasi parsial cukup berarti. Hal ini menunjukkan bahwa hipotesis ada hubungan yangsignifikan antara minat baca siswa dengan hasil belajar fisika siswa terbukti.Hasil belajar dapat ditingkatkan dengan cara meningkatkan Minat Baca siswa. Karena hubungan antara minat baca dengan hasil belajar tidak dapat dipisahkan, dengan membaca siswa akan lebih banyak pengetahuan yang didapat terutama dalam pelajaran fisika.

Faktor internal maupun faktor eksternal dapat mempengaruhi minat baca siswa. Agar siswa gemar untuk membaca terutama buku fisika perlu adanya dukungan dari lingkungan, baik lingkungan sekolah ataupun keluarga.Lingkungan sekolah dapat mendukung dengan menyediakan perpustakaan dengan buku-buku yang lengkap tentang fisika.Faktor pendukung lainnya yaitu faktor internal dari diri siswa itu sendiri.Tanpa adanya kemauan dan keinginan yang kuat maka sulit untuk siswa minat baca dalam dirinya.

Berdasarkan hasil analisis penelitian bahwa terdapat hubungan antara minat baca dengan hasil belajar, artinya semakin tinggi minat baca yang dimiliki oleh siswa maka semakin tinggi hasil belajarnya.

\section{Hubungan antara Motivasi belajar dan Minat baca dengan Hasil Belajar Fisika}

Besarnya hubungan motivasi belajar dan minat baca siswa dengan hasil belajar fisika ditunjukkan dengan besarnya koefisien korelasi sebesar 0,5771 dan koefisien determinasi parsial sebesar 0,3331 artinya konstribusi motivasi belajar dan minat baca siswa sebesar $33,3 \%$ dalam meningkatkan hasil belajar fisika Tolak $\mathrm{H}_{0}$ jika $\mathrm{t}_{\text {hit }} \geq \mathrm{t}_{(1-1 / 2 \alpha)(k, n-k-1)}$ pada taraf signifikansi $\alpha=5 \%$, dari perhitungan di atas diperoleh $F_{\text {hit }}=8,2450$ dan $F_{\text {daf }}=5,34$ dengan demikian $\mathrm{F}_{\text {hit }}>\mathrm{F}_{\text {daf }}$. Dengan kata lain $\mathrm{H}_{0}$ ditolak dan $\mathrm{H}_{1}$ diterima, yang berarti koefisien korelasi parsial cukup berarti. Hal ini menunjukkan bahwa hipotesis ada hubungan yang cukup erat antara motivasi belajar dan minat baca siswa dengan hasil belajar fisika siswa terbukti.Banyak faktor yang mempengaruhi hasil belajar di antaranya adalah intelegensi, emosi, bakat, kreativitas, minat, lingkungan sekolah, lingkungan keluarga dan lingkungan masyarakat.Hasil pembagian angket motivasi belajar dan angket minat baca siswa di atas ternyata motivasi belajar dan minat baca siswa pada pelajaran fisika mempengaruhi hasil belajar fisika. (Fahrurrozi et al., 2020) Vocabulary mastery significantly improve students' 
reading comprehension. Reading comprehension is also influenced by students' critical thinking. By having critical thinking, students will be better in reading comprehension.Para siswa yang hasil belajarnya masih rendah dikarenakan kurangnya dorongan dalam menumbuhkan motivasi dan kurangnya minat belajar. Sehingga sebagai guru harus memahami bagaimana cara memberikan dorongan yang kuat untuk menumbuhkan motivasi belajar siswa dan minat baca siswa agar hasil belajar dapat ditingkatkan. Hal ini menunjukkan bahwa hipotesis ada hubungan yang cukup erat antara motivasi belajar dan minat baca siswa dengan hasil belajar fisika terbukti. Hasil temuan ini diperkuat dengan hasil penelitian sebelumnya, yaitu oleh Ermelinda, Benge (2017) yang menunjukkan bahwa minat belajar yang tinggi dan baik, motivasi belajar yang kuat dan tinggi, maka hasil belajar yang diperoleh khususnya pada mata pelajaran IPA menjadi semakin meningkat. Dalam kegiatan belajar mengajar minat dan motivasi sangat dibutuhkan. Tanpa adanya minat dan motivasi, belajar akan menjadi sia-sia. Kekuatan hubungan kedua variabel bebas dengan hasil belajar IPA secara berurutan adalah minat belajar dan motivasi belajar.

Hasil temuan ini diperkuat dengan hasil penelitian sebelumnya, yaitu oleh Leni Marlina, Caska \& Mahdum (2017) yang menunjukkan bahwa Motivasi akan dirangsang karena ada tujuan. Motivasi ditandai dengan adanya respon dari suatu aksi yaitu tujuan. Ciri-ciri motivasi dapat diinterprestasikan dalam tingkah laku berupa rangsangan, dorongan dan pembangkit tenaga yang muncul suatu tingkah laku tertentu. (Riyanto \& Aryulina, 2020) menyatakan bahwa Learning achievement was measured using an essay test. Learning motivation and achievement data were analyzed descriptively. The results of the study showed that the implementation of immediate feedback with unlimited plus bonus points (IFUPBP) can increase student learning motivation and achievement in the Education Statistics course at Bengkulu University.Guru ekonomi merupakan faktor penting untuk meningkatkan motivasi siswa dalam belajar ekonomi. Upaya-upaya tersebut dapat menjadi pedoman bagi guru untuk meningkatkan motivasi belajar ekonomi siswa. Dalam kegiatan belajar mengajar akan berhasil baik, kalau siswa tekun mengerjakan tugas, ulet dalam memecahkan masalah dan hambatan secara mandiri. Siswa yang belajar dengan baik tidak akan terjebak pada sesuatu yang rutinitas dan mekanis. Siswa harus mampu mempertahankan pendapatnya, kalau ia sudah yakin dan dipandangnya cukup rasional. Selain itu, siswa harus peka terhadap berbagai masalah umum dan bagaimana cara memecahkan permasalahan tersebut.

Hasil temuan ini diperkuat dengan hasil penelitian sebelumnya, yaitu oleh Leo Charli, Tri Ariani, Lusi Asmara (2019) yang menunjukkan bahwa ada hubungan antara variabel bebas yaitu minat belajar dengan variabel terikat yaitu hasil belajar Fisika (Y). Dari data yang dikumpulkan tersebut kemudian dianalisis dan dilakukan pembahasan mengenai hasil penelitian.Fungsi minat sangat besar dalam mencapai hasil belajar siswa.Mulai dari keinginan untuk melakukan aktivitas dilakukan sampai akhirnya mencapai tujuan yang diharapkan bagi siswa maupun bagi orang tua siswa. Jika siswa mempunyai minat belajar yang kuat maka diharapkan belajar siswa akan baik.

(Ainy \& Pratama, 2020) menyatakan bahwa In conclusion, teachers' social competence correlation is higher than students learning motivation. Therefore, the teachers should work on their social skill to improve student learning outcomes. On the other hand, the students needs to motivate themselves.Selanjutnya Sudjana (2008) lebih menguatkan lagi pendapat para ilmuan yang menyatakan bahwa hasil belajar adalah perubahan tingkah laku sebagai hasil belajar dalam pengertian yang luas mencakup bidang kognitif, afektif, dan psikomotor. Belajar dan hasil belajar memiliki hubungan timbal-balik yang sangat erat. Hasil yang akan dicapai melalui proses belajar merupakan tujuan dari pembelajaran yang mencakup tiga ranah yaitu kognitif, afektif, dan psikomotor. Akibat dari belajar adalah kemampuan kognitif, afektif, dan psikomotor makin bertambah. Selanjutnya, Purwanto (2012) mengatakan bahwa hasil belajar adalah pemerolehan dari proses belajar siswa sesuai dengan tujuan pengajaran. Hasil angket mengenai minat dari pernyataan dikenal bahwa siswa sudah memiliki watak inisiatif dalam pembelajaran fisika, semangat belajar siswa belum optimal, kemauan belajar nampak kokoh dimana siswa mempunyai keingintahuan lewat belajar 
sendiri, siswa sudah bisa mencari jalur keluar memecahkan permasalahan dalam menguasai materi atau soal yang dialami, serta perilaku belajar siswa yang besar.

\section{Simpulan dan Saran Simpulan}

1. Ada hubungan yang signifikan antara motivasi belajar siswa dengan hasil belajar fisika. Hal ini terlihat pada $t_{\text {hit }} \geq t_{\text {daf }}$ pada taraf signifikansi $\alpha=5 \%$, dengan nilai koefesiensi korelasi $\left(r_{y 12}\right)=0,4168$ dan nilai determinasi parsial $\left(r^{2}\right.$ y12 $)=0,173$ yang bernilai positif artinya kontribusi motivasi belajar siswa sebesar 17,3\% dalam meningkatkan hasil belajar fisika.

2. Ada hubungan yang signifikan antara minat baca siswa dengan hasil belajar fisika siswa. Hal ini terlihat pada $t_{\text {hit }} \geq t_{\text {daf }}$ pada taraf signifikansi $\alpha=5 \%$, dengan nilai koefesiensi korelasi $\left(r_{y 21}\right)=0,5159$ dan nilai determinasi parsial $\left(r^{2}\right.$ y21 $)=0,266$ yang bernilai positif artinya kontribusi minat baca siswa $26,6 \%$ dalam meningkatkan hasil belajar fisika.

3. Ada hubungan yang signifikan antara motivasi belajar siswa dan minat baca siswa dengan hasil belajar fisika siswa. Hal ini terlihat pada $t_{\text {hit }} \geq t_{\text {daf }}$ pada taraf signifikansi $\alpha=5 \%$,dengan nilai koefisien korelasi $(R)=0,5771$ dan nilai koefisien determinasi $(R$

2 ) sebesar= 0,3331 yang bernilai positif artinya kontribusi motivasi belajar dan minat baca siswa sebesar 33,3\% dalam meningkatkan hasil belajar fisika siswa.

\section{Saran}

Ada pula saran yang bisa di informasikan selaku tindak lanjut dari penelitian ini adalah untuk penelitian berikutnya hasil penelitian ini dapat digunakan sebagai acuan untuk mengembangkan penelitian sejenis, terutama penelitian hubungan antara motivasi belajar dan minat baca siswa dengan hasil belajar fisika. Peneliti dapat meneliti hubungan antara motivasi belajar dan minat baca siswa dengan hasil belajar fisika dengan materi yang berbeda. Peneliti bisa melaksanakan penelitian buat variabel lain supaya bisa mengenali variabel yang lebih kokoh untuk meningkatkan Hasil belajar fisika siswa. Peneliti harus memahami tentang karakteristik cara belajar siswa dan siswa yang dijadikan sampel hendaknya diberikan pemahaman yang jelas tentang pembelajaran dengan pendekatan yang digunakan. Untuk memperoleh hasil belajar fisika dengan hasil yang lebih baik, siswa hendaknya selalu dilatih untuk mengerjakan soal-soal yang dapat mengukur kemampuan mereka.

\section{Daftar Pustaka}

Ainy, Q., \& Pratama, H. (2020). Teacher social competence, student learning motivation, and learning outcomes in English subject. ELT Forum: Journal of English Language Teaching. https://doi.org/10.15294/elt.v9i1.38131

Charli, L., Ariani, T., \& Asmara, L. (2019). Hubungan Minat Belajar terhadap Prestasi Belajar Fisika. Science and Physics Education Journal (SPEJ), 2(2), 52-60. https://doi.org/10.31539/spej.v2i2.727

Ermelinda, Benge. (2017). Hubungan Antara Minat Dan Motivasi Belajar Dengan Hasil

Belajar IPA Pada siswa SD Journal of Education Technology. Vol. 1 No. (4) pp. 231238. Terdapat pada ejournal.undiksha.ac.id.

Ebrahim, E. A. (2016). Multivariate Analysis of Factors Influencing Achievement of Students in Selected Subjects at Secondary School Level: A Case Study of Grade 10 Students at Hawassa City, Ethiopia. In Type: Double Blind Peer Reviewed International Research Journal Publisher: Global Journals Inc.

Fahrurrozi, Rachmadtullah, \& Hasanah, U. (2020). The influence of reading interests, vocabulary mastery and critical thinking on reading comprehension in elementary school students. International Journal of Psychosocial Rehabilitation. 
Fitrianingsih, Muharam, L. O., \& B, S. S. (2017). Hubungan motivasi belajar dengan minat baca di perpustakaan pada siswa SMP Negeri 5 Kendari. Jurnal Belajar Bimbingan Dan Konseling.

HUBUNGAN MOTIVASI BELAJAR DAN MINAT BACA DENGAN HASIL BELAJAR IPS. (2019). Joyful Learning Journal. https://doi.org/10.15294/jlj.v8i4.33306

Khairuddin, Z. (2013). A Study of Students' Reading Interests in a Second Language. International Education Studies. https://doi.org/10.5539/ies.v6n11p160

Kusuma, C. S. D. (2017). Counteract hoax through reading interest motivation. International Journal of Business Quantitative Economics and Applied Management Research.

Leni Marlina, Caska \& Mahdum. (2017). Hubungan minat baca dan motivasi belajar dengan hasil Belajar ekonomi siswa kelas XI Ips SMAN 10 Pekanbaru. Pekbis Jurnal, Vol.9, No.1, 33- 47. Terdapat www.neliti.com/id/publications.

Mariana, E. (2018). PENGARUH KELENGKAPAN PERANGKAT PEMBELAJARAN TERHADAP HASIL BELAJAR FISIKA SISWA SMP KARTIKATAMA METRO KELAS VIII. Justek : Jurnal Sains Dan Teknologi. https://doi.org/10.31764/justek.v1i1.414

Muhibbin. (2011). Psikologi Pendidikan. PT Remaja Rosdakarya, Bandung

Mulyani, \& Nurliana. (2017). Hubungan antara Minat Baca terhadap Kemampuan Membaca pada siswa kelas IV Sd Negeri 32 Banda Aceh. Tunas Bangsa.

Nurdin, -. (2012). Pengaruh Minat Baca, Pemanfaatan Fasilitas dan Sumber Belajar Terhadap Prestasi Belajar IPS Terpadu SMP Negeri 13 Bandar Lampung. Jurnal Ekonomi Dan Pendidikan. https://doi.org/10.21831/jep.v8i1.710

Nursalina, A. I., \& Budiningsih, T. E. (2014). Hubungan Motivasi Berprestasi Dengan Minat Membaca Pada Anak. Educational Psychology Journal.

OECD. 2018. PISA 2018 Insights and Interpretations, PISA, OECD Publishing. https://www.oecd.org/pisa/publications/pisa-2018-results.htm.

Purwanto, Ngalim. (2012). Prinsip-prinsip dan Teknik Evaluasi Pengajaran. Bandung:remaja Rosdakarya.

Riyanto, \& Aryulina, D. (2020). Implementing immediate feedback with unlimited plus bonus points to increase college student learning motivation and achievement. International Journal of Instruction. https://doi.org/10.29333/iji.2020.13327a

safitri, A. Hasmunir. Kamaruddin, T. (2017). Hubungan Minat Baca dan Motivasi Belajar dengan Hasil Belajar IPS Terpadu Siswa Kelas VII MTsN Kutabaro. Jurnal IImiah Mahasiswa Pendidikan Geografi FKIP Unsyiah.

SARI, A. (2018). Pengaruh Minat Baca Dan Motivasi Belajar Terhadap Hasil Belajar Siswa Kelas Xi lis Pada Mata Pelajaran Ekonomi Di Sma Negeri 1 Mojosari. Jurnal Pendidikan Ekonomi (JUPE).

Sudjana, Nana. (2008). Penilaian Hasil Proses Belajar Mengajar. Bandung: Remaja Rosda Karya.

Ulfah, Y., An'nur, S., \& Mahardika, A. I. (2015). Hubungan Antara Minat dan Motivasi Dengan Hasil Belajar Fisika Siswa Kelas X SMAN 10 Banjarmasin. Berkala IImiah Pendidikan Fisika, 3(2), 146. https://doi.org/10.20527/bipf.v3i2.755 